www.jmscr.igmpublication.org

Impact Factor 5.244

Index Copernicus Value: 83.27

ISSN (e)-2347-176x ISSN (p) 2455-0450

crossref DOI: _https://dx.doi.org/10.18535/jmscr/v4i11.109

Journal Of Medical Science And Clinical Research

IGM Publication

An official Publication of IGM Publication

\title{
Assessment for Risk Factors of Non-communicable Diseases in Employees (Teaching and Non-Teaching) Working in Medical College, Maharashtra
}

\author{
Authors \\ Rupali Sabale $^{1}$, Nikita Irani ${ }^{2}$, Zameer Ahmed Jatoo ${ }^{3}$ \\ ${ }^{1}$ Assistant Professor, Department of Community Medicine, K J Somaiya Medical College, Mumbai, \\ Maharashtra, India \\ ${ }^{2,3}$ Ex-Intern, K J Somaiya Medical College, Mumbai, Maharashtra, India \\ Corresponding Author \\ Rupali Sabale \\ Department of Community Medicine, K J Somaiya Medical College, Mumbai, Maharashtra, India \\ Email: rupalivsabale@gmail.com,rupali@somaiya.eduPhone:022-24090253
}

\begin{abstract}
Most Non Communicable Diseases are the result of four particular behaviours viz. tobacco use, physical inactivity, unhealthy diet, and the harmful use of alcohol. Employees working in Medical Colleges are assumed to have advantage as they have access to health care services. However, there is paucity of research to assess NCD risk factors amongst employees working in Medical College. Thus, a study was formulated with objectives of assessing the risk factors of NCD amongst all the employees working in Medical College and to find association of gender with NCD risk factor. After an ethical committee approval and permission from institutional authority, a cross-sectional study was study from June 2015 to August 2015 on teaching and nonteaching employees selected by convenience sampling. A written informed consent was taken. Ninety seven study subjects were interviewed with pre-tested questionnaire and physical measurements and blood pressure recorded. Data was analyzed using SPSS version 16. Results showed that percentage who currently smoke tobacco and drink alcohol were $6.2 \%$ and $13.4 \%$ respectively. Mean number of dayfruits and vegetables consumed were $4 \pm 2.4(S D)$ days and $6 \pm 1.5$ (SD) days respectively. Prevalence of overweight and generalised obesity were as $24.7 \%$ and $56.7 \%$ respectively. Prevalence of abdominal obesity in males and females were $55.5 \%$ and $63.5 \%$ respectively. Physical inactivity was highly prevalent. There is a need for Worksite Wellness Program in the Medical College to reduce the NCD risk factors amongst the employees.

Keywords- NCD risk factors, Employees (Teaching and Non-teaching), Medical College, Workplace.
\end{abstract}

\section{INTRODUCTION}

Noncommunicable diseases (NCDs), also known as chronic diseases, are not passed from person to person. They are of long duration and generally slow progression. The four main types of noncommunicable diseases are cardiovascular diseases (like heart attacks and stroke), cancers, chronic respiratory diseases (such as chronic obstructed pulmonary disease and asthma) and diabetes. Most non communicable diseases are the result of four particular behaviours (tobacco use, physical inactivity, unhealthy diet, and the harmful use of alcohol) that lead to four key metabolic/physiological changes (raised blood 
pressure, overweight/obesity, raised blood glucose and raised cholesterol $)^{[1]}$. The rise of noncommunicable diseases and their impact in low- and middle-income countries has gained increased attention in recent years ${ }^{[2]}$. People who die prematurely from noncommunicable diseases die from preventable heart disease, strokes, diabetes, cancers and asthma as a result of increased levels of exposure to tobacco use, unhealthy diets, physical inactivity and the harmful use of alcohol; and ineffective and inequitable health care services for people with noncommunicable diseases ${ }^{[3]}$. Employees working in Medical Colleges are assumed to have additional advantage as they have access to health care services. However, there is paucity of research to assess NCD risk factors amongst employees working in Medical College. Moreover, employees (teaching and non-teaching staff) working in Medical College play a crucial role in reducing the NCD risk factors amongst general population and thereby non - communicable diseases. They are the ones who teach students about NCD risk factors and also educate patients or community about risk factors. Thus, a study was formulated with primary objective of assessing the risk factors of NCD amongst all the employees working in Medical College. We included both teaching and non teaching staff, because both staff contributes to the overall culture of any institute and both directly or indirectly influences the student / patient and / or community. The secondary objective was to find association of gender with NCD risk factor. Traditionally, risk factors for Cardiovascular Diseases have been categorized as behavioural, anthropometric and biochemical ${ }^{[4]}$. In the present study, we focussed only on behavioural and anthropometric risk factors. Biochemical analysis could not be done due financial non feasibility.

\section{MATERIAL AND METHODS}

The study was conducted in one of the Medical Colleges located in the city of Mumbai affiliated to Maharashtra University of Health Sciences. Prior to the study, an ethical committee approval was obtained from Institutional Ethical Committee. Permission from the Head of the institution was also obtained for collection of data. List of employees was obtained from institute's administration department. Teaching staff were those involved in teaching medical students. Those are Professor, Associate and Assistant Professor, and Tutors. Nonteaching staff are clerks, attendants, technicians, medical social workers etc. working in Medical College. Study subjects were selected using convenience sampling technique. For this, all employees were approached through their respective Head of the Department. Time-table regarding assessment of NCD risk factors was communicated to each department. The investigator then approached each department as per the date schedule, explained about the study, and invited them to voluntarily participate. All those who were contacted, willingly accepted to participate in the study. A written informed consent of each participant was taken for this cross-sectional study. One of the researchers was always available to answer any query asked by any participant. Data was collected from June 2015 to August 2015. The study subjects were interviewed with a pre-tested questionnaire to assess the NCD risk factors such as dietary intake, physical activity, tobacco consumption in smoke or smokeless form and alcohol consumption. The questionnaire also included questions pertaining to whether currently on hypertensive, diabetic and/or cholesterol lowering drugs. Anthropometric assessment for weight, height and waist circumference was also done. Blood pressure (BP) was recorded by using Omron Model - 5 Automatic Blood Pressure Monitor. Three readings of BP were taken and average of last two BP readings were considered as final $\mathrm{BP}{ }^{[5]}$. Participants were considered as tobacco users if they were currently consuming tobacco products. Those consuming fruit and vegetable for less than or equal to 4 days/week were considered as persons not meeting dietary recommendations ${ }^{[6]}$. Person was considered physically inactive if he/she does not do physical activity for three or more days of vigorous-intensity activity of at least 20 minutes 
per day or 5 or more days of moderate-intensity activity or walking of at least 30 minutes per day or 5 or more days of any combination of walking, moderate- or vigorous intensity activities. WHO Asia Pacific guidelines ${ }^{[7]}$ were used to define overweight as body mass index (BMI) $\geq 23 \mathrm{~kg} / \mathrm{m}^{2}$ but $<25 \mathrm{~kg} / \mathrm{m}^{2}$, generalized obesity as, BMI $\geq 25 \mathrm{~kg} / \mathrm{m}^{2}$ ) and abdominal obesity as waist circumference $\geq 90 \mathrm{~cm}$ for men and $\geq 80 \mathrm{~cm}$ for women.

Data was analyzed using SPSS version 16 . Continuous variables were expressed in mean \pm SD. The categorical variables and prevalence of risk factors were expressed as frequencies and percentages. Student's unpaired t test was used to compare groups for continuous variable and chisquare test was used to compare proportions between two groups

\section{RESULTS}

Total study subjects enrolled were 97 . Out of 97 employees, 52 were females $(53.6 \%)$ and 45 were males $(46.4 \%)$. Mean age was $43.63 \pm 8.42$ (SD) years. There was no statistical difference between mean age of males and females. Percentage who currently smoke tobacco and those who smoke daily were $6.2 \%$ and $4.1 \%$ respectively. Percentage who currently drink (drank alcohol in the past 30 days) and drink daily were $13.4 \%$ and $7.2 \%$ respectively. Mean number of day fruits and vegetables consumed were $4 \pm 2.4$ (SD) days and $6 \pm 1.5$ (SD) days respectively. Percentages not consuming daily fruit and vegetables were $64.9 \%$ and $42.3 \%$. Prevalence of overweight and generalised obesity were as $24.7 \%$ and $56.7 \%$ respectively. Prevalence of abdominal obesity in males and females were $55.5 \%$ and $63.5 \%$ respectively. There was statistical difference between mean weights of males and females. Mean systolic and diastolic blood pressure of males were statistically higher than mean systolic and diastolic blood pressure of females (Table 1).Prevalence of hypertension (currently on medications for raised blood pressure) was $19.6 \%$. Percentage with raised BP (SBP 140 and/or DBP 90 $\mathrm{mmHg}$ ) who are not currently on medication for raised BP was $11.3 \%$. Prevalence of Diabetes Mellitus (currently on medications for raised blood sugar) was $9.3 \%$. Prevalence of DM was significantly high in males as compared to females (15.6\% in males and $3.8 \%$ in females). Physical inactivity for vigorous intensity was significantly high in females as compared to males. Tobacco (smoke or smokeless) and alcohol consumption was significant high in males as compared to females. (Table 2)

Table 1: Comparison of blood pressure and anthropometry measurement between males and females

\begin{tabular}{|l|c|c|c|}
\hline Anthropometric parameter & Males & Females & P value \\
\hline Mean systolic blood pressure & $126.03 \pm 18.3$ & $118.2 \pm 18.4$ & $0.03 *$ \\
\hline Mean diastolic blood pressure & $78.13 \pm 11.2$ & $72.8 \pm 11.4$ & $0.02 *$ \\
\hline Mean weight & $68.24 \pm 11.7$ & $63.2 \pm 11.9$ & $0.04 *$ \\
\hline Mean waist circumference & $91.3 \pm 10.3$ & $92.4 \pm 10.6$ & 0.61 \\
\hline Mean BMI & $24.4 \pm 3.8$ & $25.9 \pm 3.9$ & 0.06 \\
\hline
\end{tabular}

* Statistically significant difference 
Table 2: Comparison of behavioral risk factors between male and females

\begin{tabular}{|l|c|c|c|c|c|}
\hline \multirow{2}{*}{ Behavioural Risk Factors } & \multicolumn{2}{|c|}{ Males $(\mathrm{n}=45)$} & \multicolumn{2}{c|}{ Females $) \mathrm{n}=52)$} & \multirow{2}{*}{ P value } \\
\cline { 2 - 6 } & Freq & $\%$ & Freq & $\%$ & \\
\hline Physical inactivity -for vigorous exercises & 35 & 77.8 & 49 & 94.2 & $0.01^{*}$ \\
\hline Physical inactivity - for moderate exercises & 41 & 91.1 & 50 & 96.2 & 0.31 \\
\hline Below dietary recommendations for fruits & 29 & 64.4 & 22 & 42.3 & $0.03^{*}$ \\
\hline Below dietary recommendations for vegetables & 15 & 33.3 & 7 & 13.5 & $0.02^{*}$ \\
\hline Habit of salt consumption & 20 & 44.4 & 21 & 40.4 & 0.69 \\
\hline Habit of eating processed food & 33 & 73.3 & 44 & 84.6 & 0.18 \\
\hline Smoke form of tobacco consumption & 6 & 13.3 & 0 & 0.0 & $0.007^{*}$ \\
\hline Smokeless form of tobacco consumption & 5 & 11.1 & 3 & 5.8 & $0.007^{*}$ \\
\hline Alcohol consumption & 12 & 26.7 & 1 & 1.9 & $0.0002^{*}$ \\
\hline
\end{tabular}

* Statistically significant difference

\section{DISCUSSION}

The present study is focussing on the NCD risk factors amongst employees in the Medical College. There are various studies conducted to assess the NCD risk factors at workplace. But the study subjects are usually the health care employees and their families ${ }^{[8]}$, industrial workers ${ }^{[9]}$, Medical students ${ }^{[10]}$ etc. There are few studies which assess all the behavioural and biological risk factors in all the employees (teaching and non-teaching) working in Medical College.

Thakur JS et al ${ }^{[11]}$ got the prevalence across smoking among adult men in India as $24.3 \%$. According to NFHS-III ${ }^{[12]}$ the percentage of men and women in Maharashtra who drink alcohol is $24 \%$ and $0.4 \%$ respectively. Similarly percentage of men and women in Maharashtra using any kind of tobacco is $48.2 \%$ and $10.5 \%$. In the present study the favourable findings are that the tobacco and alcohol consumption is much lower than the national and state figures. This is similar to conclusion derived by Ketkar et al ${ }^{[6]}$ study on employees of health-care institution. One of the reasons, may be that study focuses employees of medical college, who are directly or indirectly get exposed to the knowledge regarding ill effects of tobacco and alcohol. Thus, employees may not be habituated to tobacco and/or alcohol consumption. Moreover, in the present study setting, tobacco and alcohol consumption is not permitted leading to lower consumption of tobacco and/or alcohol. But to strategically reduce prevalence of tobacco and alcohol consumption to zero, continuous awareness program and screening for ill effects of tobacco at workplace are required.

Non Communicable Diseases risk factors assessed in seven states (Andhra Pradesh Mizoram Kerala Tamil Nadu Madhya Pradesh Uttarakhand Maharashtra), mentions that in a week, mean number of days people consumed fruits is for about 2-3 days and vegetables about 4-7 days ${ }^{[13]}$. In the present study, mean number of day fruits and vegetables consumed were $4 \pm 2.4$ (SD) days and 6 \pm 1.5 (SD) days respectively. The mean intake of fruits and vegetables in the present study is little higher than the state average. Sachdeva $S$ et al ${ }^{[14]}$ has cited that the general recommendation for intake of fruit and vegetables is at least 400 grams per person per day (five serving of $80 \mathrm{~g}$ each day). Thus, as a protective factors against NCD, the individual needs to have daily fruit and vegetable 
consumption. In the present study, $64.9 \%$ and $42.3 \%$ were not eating fruits and vegetables daily respectively. The reason which we observed was that many of them, are habituated to eating non vegetarian food (chicken, meat and/or fish) on few specific days (mostly Wednesday, Friday and Sunday) especially for dinner. According to them, it is their custom to eat non vegetarian food on those days. Thus, they skip eating vegetables and fruits on those days. Moreover, the institute do not provide non vegetarian food in their canteen. This has an additional advantage, as employee has no choice but to eat vegetarian food, if they do not bring their lunch box. But, presently in the canteen whole fruits are not served. Thus, to increase the intake of fruits, awareness can be generated to carry fruits in the lunch boxes, and/or fruits can be provided in the canteen.

Findings from results from the ICMR-INDIAB study (Phase-1) ${ }^{[15]}$ states that $65.4 \%$ of population in Maharashtra is inactive. Their study concludes that a large percentage of people in India are inactive with fewer than $10 \%$ engaging in recreational physical activity. Insufficient physical activity is one of the ten leading risk factors for global mortality. People who are insufficiently physically active have a $20 \%$ to $30 \%$ increased risk of all-cause mortality compared to those who engage in at least 150 minutes of moderate intensity physical activity per week, or equivalent, as recommended by $\mathrm{WHO}^{[16]}$. In the present study, also fewer than $10 \%$ are indulging into any kind of WHO recommended physical activity. This is the major concern. It was observed that, many were not aware about the WHO recommendation for physical activity required for protection against NCD. Most the employees, walk for almost 10 to 15 minutes to reach the college from railway station. Thus, many felt they are indulging into physical activity, but were not aware of need of vigorous and/or moderate intensity physical activity. There is urgent need to address this issue. Millet et al ${ }^{[17]}$ in the study concluded that walking and bicycling to work was associated with reduced cardiovascular risk in the Indian population. To begin with, an awareness should be generated regarding brisk walking, which is relatively practical to all to do it. However, as a long term goal, an awareness program at workplace is also required regarding physical activity. In the present study setting, Physiotherapy College Wing is attached to Medical College. Thus, it is relatively easier for employees to do moderate and vigorous activity by enrolling themselves in physical training programmes conducted by Physiotherapy College. Also, Municipal Corporation of Greater Mumbai (MCGM) has set-up open gymnasium in some of the public grounds. Thus, employees need to be sensitized regarding importance of physical activity to reduce risk of NCD, so that they can avail the services that are available at the workplace, as well as in their vicinity of the residence. Especially, women employees must be made aware of open gymnasium and/or facilities at Physiotherapy, as physical inactivity for vigorous intensity was statistically higher amongst them as compared to males. Males, those who were indulging in vigorous activities, were playing cricket, football, or were going to gymnasium.

Pradeepa $\mathrm{R}$ et $\mathrm{al}^{[18]}$ in their study got the prevalence of generalized obesity and abdominal obesity as $16.6 \%$ and $18.7 \%$ in Maharashtra. In the present study, the prevalence of generalized obesity and abdominal obesity is much higher than the state figures. Physical inactivity was also highly prevalent in the present study, which may be the contributory factor for obesity. Amongst all four risk factors (physical inactivity, diet, tobacco and alcohol), physical activity is seen as the most common risk factors. Due to physical inactivity, a metabolic / physiological change that is observed in this group is obesity. It was observed, that many were aware that they had abdominal obesity, but were not aware of the ways to reduce obesity. Moreover, they felt the need to reduce obesity especially waist circumference for a cosmetic look as well. This felt need can be a stepping stone to gradually sensitize the employees for risk factors for NCD.

Anchala $\mathrm{R}$ et al ${ }^{[19]}$, got the prevalence of hypertension as $33 \%$ in urban India. In the present 
study, the prevalence was $19.6 \%$ which is much lower. But still, efforts are needed to bring down this hypertension prevalence and ensuring compliance to medications to reduce complications due to hypertensions.

However, as with any study, this study do has limitations. There can reporting bias from the participants for revealing behaviour of tobacco and alcohol consumption. All the participants were from single medical college located in urban areas. Therefore the findings cannot be generalized across all the medical colleges in India. However, as said earlier, there is paucity of literature on assessing NCD risk factors in the employees working in the Medical College. Thus similar type of large scale studies are required. If the results are similar, it is required to design the Prevention Program especially Physical Training Program at workplace (Medical College). Workplace wellness programs ${ }^{\text {[20] }}$ are an important strategy to prevent the major shared risk factors for CVD and stroke, including cigarette smoking, obesity, hypertension, dyslipidemia, physical inactivity, and diabetes.

\section{CONCLUSIONS}

Physical inactivity and obesity are highly prevalent in employees working in Medical College. Worksite wellness program should be conducted in the Medical College to reduce the NCD risk factors amongst the employees.

\section{ACKNOWLEDGEMENT}

We are grateful to college authorities for permitting us to conduct the study. We are also thankful to employees for participating in this study.

\section{REFERENCES}

1. Jun;32(6):1170-7. doi: 10.1097/HJH.0000000000000146. Review. PubMed PMID: 24621804WHO: Risk Factors. Available online at:http://www.who.int/gho/ncd/risk_factors/en/ (Last accessed on 16th Nov 2016)

2. Miranda JJ, Kinra S, Casas JP, Smith GD, Ebrahim S. Non-communicable diseases in low- and middle-income countries: context, determinants and health policy. Tropical medicine \& international health: TM \& IH. 2008;13(10):1225-1234. doi:10.1111/j.13653156.2008.02116.x.

3. NCDs | Noncommunicable diseases and their risk factors. Available online at: http://www.who.int/ncdnet/about/4diseases/e $\mathrm{n} /$ (Last accessed on 16th Nov 2016)

4. Bela Shah and Prashant Mathur. Surveillance of cardiovascular disease risk factors in India: The need \& scope. Indian J Med Res. 2010 Nov; 132(5): 634-642. doi: 10.4103/0971-5916.73420

PMCID: PMC3028945

5. WHO - STEPS: Available online athttp://www.who.int/chp/steps/Part3_Sectio n3.pdf?ua $=1$ (Last accessed on 16th Nov 2016)

6. A.R. Ketkar, S.K. Veluswamy, N. Prabhu, A.G. Maiya. Screening for noncommunicable disease risk factors at a workplace in India: a physiotherapy initiative in a healthcare setting. Hong Kong J Physiother, 33 (2015), p. 3-9

7. World Health Organization. The AsiaPacific perspective: redefining obesity and its treatment. Geneva, Switzerland: World Health Organization; 2000.

8. D. Sharma, M. Vatsa, R. Lakshmy, R. Narang, V.K. Bahl, S.K. Gupta. Study of cardiovascular risk factors among tertiary hospital employees and their families. Indian Heart J, 64 (2012), pp. 356-363

9. Kishore J, Kohli C, Sharma PK, Sharma E. Noncommunicable disease risk profile of factory workers in Delhi. Indian Journal of Occupational and Environmental Medicine. 2012;16(3):137-141. doi:10.4103/00195278.111761.

10. Rao CR, Darshan B, Das N, Rajan V, Bhogun M, Gupta A. Practice of Physical Activity among Future Doctors: A Cross Sectional Analysis. International Journal of Preventive Medicine. 2012;3(5):365-369. 
11. Thakur JS, Garg R, Narain JP, Menabde N. Tobacco use: a major risk factor for non communicable diseases in South-East Asia region. Indian J Public Health. 201. JulSep;55(3):155-60. doi: 10.4103/0019557X.89943. PubMed PMID: 22089682.

12. International Institute for Population Sciences (IIPS) and Macro International. 2007. National Family Health Survey (NFHS-3), 2005-06: India: Volume I.Mumbai: IIPS.

13. National Institute of Medical Statistics, Indian Council of Medical Research (ICMR), 2009, IDSP Non-Communicable Disease Risk Factors Survey, Phase-I States of India, 2007-08. National Institute of Medical Statistics and Division of NonCommunicable Diseases, Indian Council of Medical Research, New Delhi, India.

14. Sachdeva S, Sachdev TR, Sachdeva R. Increasing Fruit and Vegetable Consumption: Challenges and Opportunities. Indian Journal of Community Medicine: Official Publication of Indian Association of Preventive \& Social Medicine. 2013;38(4):192-197. doi:10.4103/0970-0218.120146.

15. Anjana et al.: Physical activity and inactivity patterns in India - results from the ICMRINDIAB study (Phase-1) [ICMR-INDIAB5]. International Journal of Behavioral Nutrition and Physical Activity 2014 11:26.

16. WHO | Prevalence of insufficient physical activity. Available online athttp://www.who.int/gho/ncd/risk_factors/ph ysical_activity_text/en/(last accessed on 16th Nov 2016)

17. Millett C, Agrawal S, Sullivan R, et al. Associations between Active Travel to Work and Overweight, Hypertension, and Diabetes in India: A Cross-Sectional Study. Bhalla K, ed. PLoS Medicine. 2013;10(6): e1001459. doi:10.1371/journal.pmed.1001459.

18. Pradeepa R, Anjana RM, Joshi SR, et al. Prevalence of generalized \& abdominal obesity in urban \& rural India- the ICMR INDIAB Study (Phase-I) [ICMR - INDIAB$3]$. The Indian Journal of Medical Research. 2015;142(2):139-150. doi:10.4103/09715916.164234

19. Anchala R, Kannuri NK, Pant H, Khan H, Franco OH, Di Angelantonio E, Prabhakaran D. Hypertension in India: a systematic review and meta-analysis of prevalence, awareness, and control of hypertension. $\mathbf{J}$ Hypertens. 2014 ; PubMed Central PMCID: PMC4011565.

20. Worksite Wellness Programs for Cardiovascular Disease Prevention Mercedes Carnethon, Laurie P. Whitsel, Barry A. Franklin, Penny Kris-Etherton, Richard Milani, Charlotte A. Pratt and Gregory R. Wagner Circulation. 2009;120:1725-1741, originally published October 26, 2009http://dx.doi.org/10.1161/CIRCULATIONAHA.109.192653 